\title{
GCU
}

Glasgow Caledonian

University

University for the Common Good

\section{State feedback linearized model for phase-controlled series-parallel resonant converters}

Aboushady, A.A.; Ahmed, K.H.; Finney, S.J.; Williams, B.W.

Published in:

IECON 2011 - 37th Annual Conference of the IEEE Industrial Electronics Society

DOI:

10.1109/IECON.2011.6119544

Publication date:

2011

Document Version

Author accepted manuscript

Link to publication in ResearchOnline

Citation for published version (Harvard):

Aboushady, AA, Ahmed, KH, Finney, SJ \& Williams, BW 2011, State feedback linearized model for phasecontrolled series-parallel resonant converters. in IECON 2011'-37th Annual Conference of the IEEE Industrial Electronics Society. IEEE, IECON 2011 - 37th Annual Conference on IEEE Industrial Electronics Society, Melbourne, Australia, 7/11/11. https://doi.org/10.1109/IECON.2011.6119544

\section{General rights}

Copyright and moral rights for the publications made accessible in the public portal are retained by the authors and/or other copyright owners and it is a condition of accessing publications that users recognise and abide by the legal requirements associated with these rights.

Take down policy

If you believe that this document breaches copyright please view our takedown policy at https://edshare.gcu.ac.uk/id/eprint/5179 for details of how to contact us. 


\title{
State Feedback Linearized Model for Phase- Controlled Series-Parallel Resonant Converters
}

\author{
A.A.Aboushady ${ }^{*}$, K.H.Ahmed ${ }^{+}$, S.J.Finney ${ }^{*}$, B.W.Williams ${ }^{*}$ \\ "Department of Electronic and Electrical Engineering \\ Strathclyde University, Glasgow, UK \\ ${ }^{+}$Electrical Engineering Department, Faculty of Engineering \\ Alexandria University, Alexandria, Egypt
}

\begin{abstract}
This paper proposes a linearized large-signal state space model for phase-controlled series-parallel resonant converter. The model combines multiple-frequency and average state-space modeling techniques to generate a universal model with DC state variables that are easier to control compared to the fast resonant tank dynamics. In order to perform linearization, the proposed model utilizes a state feedback scheme from output filter inductor current. The model also serves as a tool for large signal prediction/estimation of converter state variables. The model accuracy was verified by comparing with a detailed switching model of the converter built in MATLAB simulation environment.
\end{abstract}

Index Terms- Large-signal, phase control, Series-parallel resonant converter (SPRC), state feedback.

\section{INTRODUCTION}

$\mathrm{DC} / \mathrm{DC}$ resonant converters have been an attractive alternative to hard-switched PWM converters in DC power supply applications. This is due to their soft switching characteristics, hence offering the possibility of boosting switching frequency. This makes them feasible for modular power supplies with high power density.

Several types of resonant converters have been applied in DC power supply applications. Series resonant converters have poor no-load regulation, poor short circuit charactersistics and need a big output filter capacitor. However its switching losses decrease with load decrease. They are suitable for high-output-voltage low-output-current converters [1-6]. Parallel resonant converters have better no-load regulation and are naturally short circuit proof. However, high circulating resonant tank current means higher switching losses and the converter is better suited to applications with relatively narrow input voltage range $[7,8]$. The combination series-parallel resonant converter (SPRC) combines advantages of both and eliminates their drawbacks. It can run over a large input voltage range and a large load range (no load to full load) while maintaining excellent efficiency [9-11].

Various control techniques have been used for control of resonant converters. These can be broadly classified into variable frequency and fixed-frequency approaches. Variable frequency techniques include average-current control, frequency control, capacitor voltage control, diode-conduction-angle control, and optimal trajectory control [11-13]. However, these variable frequency techniques present practical disadvantages, like a wide noise spectrum which makes it difficult to control EMI, more complex filtering and poor utilization of magnetic components. Fixed-frequency techniques like phaseshift modulation [14-16] overcome problems of variablefrequency control and offer excellent control on the output voltage. For the aforementioned reasons, this paper focuses on fixed-frequency phase control of SPRC.

Modeling of resonant converters is more complex than PWM converters. This is mainly due to the non-linear coupling of its $\mathrm{AC}$ and $\mathrm{DC}$ state variables. Various modeling techniques have been proposed in literature for SPRC. Steadystate operation has been analyzed by several authors [17-19], providing an insight into converter behavior and overall steady-state gain. Small-signal models for SPRC use linearized state-space models around an equilibrium point to enable stability analysis and closed loop design [20]. The resulting closed loop design, although may eliminate error in output voltage, but dynamic response is usually unsatisfactory. Small-signal models include discrete-time domain [21-23] and multiple frequency techniques [24-26]. Method based on discrete time domain modeling has been proposed for low order converters. It becomes cumbersome with higher order converters. The multiple frequencies method transforms AC signal into DC signal at multiple frequencies providing a theoretically high accuracy model [27]. Although sufficient for analysis and closed loop design, small-signal models cannot be used for large-signal estimation of converter state variables. Large-signal models based on describing function method have also been proposed for SPRC analysis [28,29]. However, due to model non-linearity, non-linear controllers such as sliding mode [30] and robust optimal control [31] were designed for control of SPRC.

In this paper, a linearized large-signal model for the SPRC is obtained using a state feedback scheme. The latter utilizes a feedback signal from output filter inductor current to aid in linearizing system model. This makes the model useful for large-signal prediction of converter $\mathrm{AC}$ and $\mathrm{DC}$ state variables.

\section{Proposed Model for the DC/DC Resonant converter}

Fig. 1 shows the circuit diagram for a typical SPRC with the main circuit parameters defined in Table I. The bridge rectifier, together with the output LC filter, acts as a non-linear load to the resonant tank circuit. Hence, the converter large-signal response cannot be modeled using linear approaches like the conventional average state-space models. 
$\mathrm{DC} / \mathrm{DC}$ resonant converters have two-stages of conversion; $\mathrm{DC} / \mathrm{AC}$ (inversion) and $\mathrm{AC} / \mathrm{DC}$ (rectification). Hence, two main subsystems exist; the $\mathrm{AC}$ sub-system (resonant tank) and the DC sub-system (output filter). This is illustrated in Fig. 2. Each of these sub-systems has its own state variables; therefore, both $\mathrm{AC}$ and $\mathrm{DC}$ state variables exist. In order to combine both types of signals into a universal model, it is essential to transform the $\mathrm{AC}$ state variables to equivalent $\mathrm{DC}$ quantities. This is obtained through the multiple frequency modeling (MFM) technique which converts the AC state variables to dq quantities (DC values with slow dynamics) using an arbitrary synchronous reference frame. The resulting DC state variables from the resonant tank are combined with the natural DC state variables on the output filter side (modeled with conventional average state-space modeling) using a linearization scheme to overcome the non-linearity imposed by the rectifier. The result is a universal large-signal linear model for the whole converter.

\section{A. AC sub-system modeling}

Fig. 3 shows the equivalent circuit diagrams for the AC subsystem of the SPRC. Three state variables exist $\left(i_{L}, v_{C S}, v_{C p}\right)$. The voltage-current relations can be described by equations (1) to (3).

$$
\begin{gathered}
v_{A B}=r_{T} i_{L}+L_{T} \frac{d i_{L}}{d t}+v_{C s}+v_{C p} \\
i_{L}=C_{s} \frac{d v_{C s}}{d t} \\
i_{L}-i_{B r}=C_{p} \frac{d v_{C p}}{d t}
\end{gathered}
$$

Multiple frequency modeling approach, introduced in [24,25] for SPRC, is utilized for modeling the AC subsystem of the resonant converter. Since the state variables have periodic characteristics, each state can be expressed with a Fourier series [26,27]. Energy transfers from input to output mainly at fundamental frequency, hence the dominant frequency for modeling and analysis of the AC sub-system state variables is assumed to be $\omega_{s}$, the operating frequency of the converter.

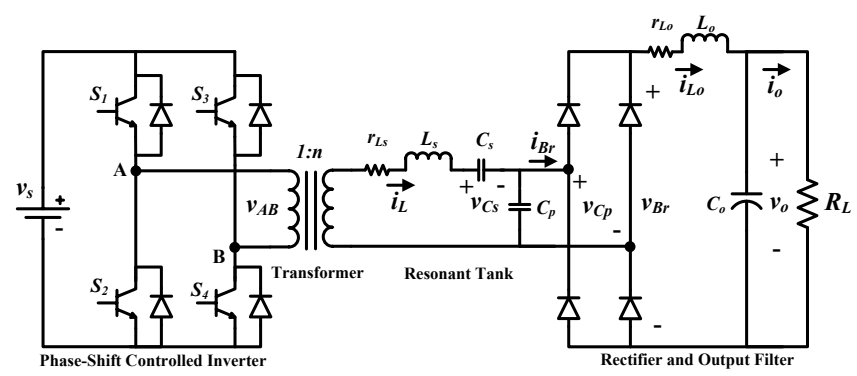

Fig. 1. Circuit Diagram for SPRC.

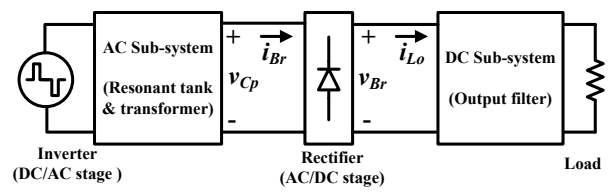

Fig. 2. Conversion stages and subsystems in typical resonant converter.

\begin{tabular}{|c|c|}
\hline Parameter & Definition \\
\hline$v_{s}$ & DC link supply voltage (V) \\
\hline$v_{A B}$ & Inverter output voltage $(\mathrm{V})$ \\
\hline$n$ & Transformer turns ratio \\
\hline$v_{A B}{ }^{\prime}$ & Inverter output voltage referred to secondary $(\mathrm{V})$ \\
\hline$r_{L s}$ & Internal resistance of resonant tank inductor $(\Omega)$ \\
\hline$L_{s}$ & Resonant tank inductance $(\mu \mathrm{H})$ \\
\hline$r_{l}$ & Parasitic resistance of transformer referred to secondary $(\Omega)$ \\
\hline$L_{l}$ & $\begin{array}{l}\text { Leakage inductance of transformer referred to secondary } \\
(\mu \mathrm{H})\end{array}$ \\
\hline$r_{T}$ & Total equivalent resistance $r_{T}=r_{l}+r_{L s}(\Omega)$ \\
\hline$L_{T}$ & Total equivalent inductance $L_{T}=L_{l}+L_{s}(\mu \mathrm{H})$ \\
\hline$C_{s}$ & Resonant tank series capacitance $(\mu \mathrm{F})$ \\
\hline$C_{p}$ & Resonant tank parallel capacitance $(\mu \mathrm{F})$ \\
\hline$r_{L o}$ & Internal resistance of output filter inductor $(\Omega)$ \\
\hline$L_{o}$ & Output filter inductance $(\mathrm{mH})$ \\
\hline$C_{o}$ & Output filter capacitance $(\mu \mathrm{F})$ \\
\hline$\omega_{s}$ & Resonant tank fundamental frequency $(\mathrm{rad} / \mathrm{s})$ \\
\hline$i_{L}$ & Resonant tank inductor current (A) \\
\hline$v_{C s}$ & Resonant tank series capacitor voltage $(\mathrm{V})$ \\
\hline$v_{C p}$ & Resonant tank parallel capacitor voltage (V) \\
\hline$i_{B r}$ & Bridge rectifier input current (A) \\
\hline$v_{B r}$ & Bridge rectifier output voltage $(\mathrm{V})$ \\
\hline $\bar{v}_{B r}$ & Average bridge rectifier output voltage $(\mathrm{V})$ \\
\hline$i_{L o}$ & Output filter inductor current (A) \\
\hline$v_{o}$ & Output voltage (V) \\
\hline$i_{o}$ & Output current (A) \\
\hline
\end{tabular}
TABLE I

DEFINITION OF CIRCUIT PARAMETERS

The state variables and input can be approximated as sinusoidal states with fundamental frequency $\omega_{s}$ as in equations (4) to $(8)$.

$$
\begin{array}{cc}
i_{L} \square i_{L d} & \omega_{s} t+i_{L q} \cos \omega_{s} t \\
v_{C s} \square v_{C s d} & \omega_{s} t+v_{C s q} \cos \omega_{s} t \\
v_{C p} \square v_{C p d} & \omega_{s} t+v_{C p q} \cos \omega_{s} t \\
v_{A B} \square v_{A B d} & \omega_{s} t+v_{A B q} \cos \omega_{s} t \\
i_{B r} \square i_{B r d} & \omega_{s} t+i_{B r q} \cos \omega_{s} t
\end{array}
$$

where, $i_{L d q}, v_{C s d q}$ and $v_{C p d q}$ are time-varying Fourier coefficients. The six Fourier coefficients, being time-dependent DC quantities, are considered as the new set of state variables.

Substituting equations (4)-(8) into equations (1)-(3), and equating sine and cosine coefficients, yields

$$
\begin{gathered}
v_{A B d}{ }^{\prime}=r_{T} i_{L d}+L_{T} \dot{i_{L d}}-L_{T} \omega_{s} i_{L q}+v_{C s d}+v_{C p d} \\
v_{A B q}{ }^{\prime}=r_{T} i_{L q}+L_{T} \dot{i_{L q}}+L_{T} \omega_{s} i_{L d}+v_{C s q}+v_{C p q} \\
i_{L d}=C_{s} \dot{v_{C s d}}-C_{s} \omega_{s} v_{C s q} \\
i_{L q}=C_{s} \dot{v_{C s q}}+C_{s} \omega_{s} v_{C s d}
\end{gathered}
$$




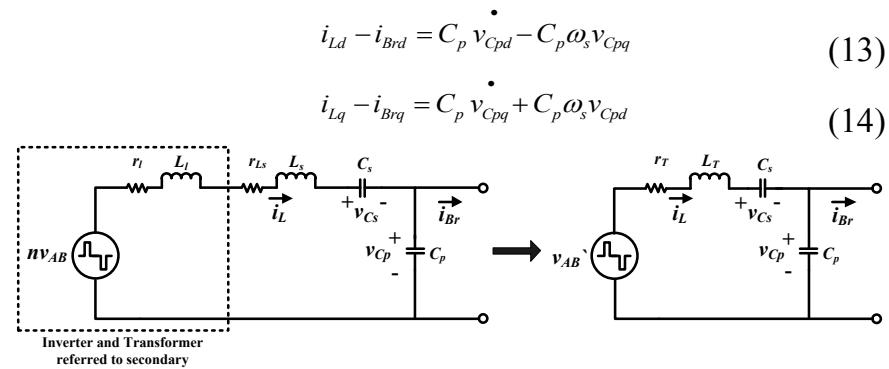

Fig. 3. Equivalent circuit diagrams for AC sub-system.

Equations (9)-(14) in state-space form

$$
\vec{x}_{1}(l)=A_{1} \vec{x}_{1}(l)+D_{1} \vec{u}(\iota)
$$

where,

$$
\begin{aligned}
& \vec{x}_{1}(\iota)=\left[\iota_{L d} i_{L q} v_{C s d} v_{C s q} v_{C p d} v_{C p q}\right]^{T}, \vec{u}_{1}(\iota)=\left[v_{A B d} v_{A B q} i_{B r d} i_{B r q}\right]^{T}, \\
& A_{1}=\left[\begin{array}{cccccc}
-\frac{r_{T}}{L_{T}} & \omega_{s} & -\frac{1}{L_{T}} & 0 & -\frac{1}{L_{T}} & 0 \\
-\omega_{s} & -\frac{r_{T}}{L_{T}} & 0 & -\frac{1}{L_{T}} & 0 & -\frac{1}{L_{T}} \\
\frac{1}{C_{s}} & 0 & 0 & \omega_{s} & 0 & 0 \\
0 & \frac{1}{C_{s}} & -\omega_{s} & 0 & 0 & 0 \\
\frac{1}{C_{p}} & 0 & 0 & 0 & 0 & \omega_{s} \\
0 & \frac{1}{C_{p}} & 0 & 0 & -\omega_{s} & 0
\end{array}\right] B_{1}=\left[\begin{array}{cccc}
\frac{1}{L_{T}} & 0 & 0 & 0 \\
0 & \frac{1}{L_{T}} & 0 & 0 \\
0 & 0 & 0 & 0 \\
0 & 0 & 0 & 0 \\
0 & 0 & -\frac{1}{C_{p}} & 0 \\
0 & 0 & 0 & -\frac{1}{C_{p}}
\end{array}\right]
\end{aligned}
$$

B. DC sub-system modeling

Fig. 4 shows the equivalent circuit diagram for the DC sub-system of the SPRC. Note that $\bar{v}_{B r}$ is the average rectifier output voltage $v_{B r}$. Energy is transferred at DC frequency, so the dominant component for modeling and analysis is the DC (average) value. For this reason, average state-space modeling, with the small-ripple assumption, is valid to use for modeling the DC sub-system. Two state variables exist $\left(i_{L o}\right.$ and $\left.v_{o}\right)$, for which the voltage-current relations can be described by (16) and (17). The bar notation denoting the average value of the state variables will be neglected for standardization of model.

$$
\begin{gathered}
\bar{v}_{B r}=r_{L o} i_{L o}+L_{o} \frac{d i_{L o}}{d t}+v_{o} \\
i_{L o}-i_{o}=C_{o} \frac{d v_{o}}{d t}
\end{gathered}
$$

Equations (16) and (17) can be used to represent the DC sub-system in state-space form,

$$
\vec{x}_{2}(\iota)=\mathrm{A}_{2} \vec{x}_{2}(\iota)+D_{2} \vec{u}(\iota)
$$

where,

$$
\vec{x}_{2}(\iota)=\left\lfloor\iota_{L o} v_{o}\right]^{T}, \vec{u}_{2}(\iota)=\left\lfloor v_{B r} i_{o}\right]^{T}, \quad A_{2}=\left[\begin{array}{cc}
-\frac{r_{L o}}{L_{o}} & -\frac{1}{L_{o}} \\
\frac{1}{C_{o}} & 0
\end{array}\right], \quad B_{2}=\left[\begin{array}{cc}
\frac{1}{L_{o}} & 0 \\
0 & -\frac{1}{C_{o}}
\end{array}\right]
$$

Fig. 4. Equivalent circuit diagram for DC sub-system.

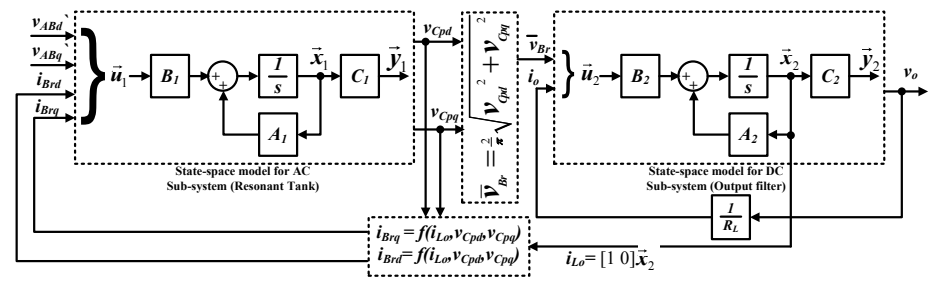

Fig. 5. Non-linear combined system model for SPRC.

\section{Combined system non-linear model}

Fig.5 shows the non-linear model for the SPRC combining the state-space linear models of the AC and DC sub-systems. The voltage-current relationship between both sub-systems (separated by the bridge rectifier) is outlined by:

- The state-variables of the AC sub-system are approximated as sinusoidal at fundamental frequency, therefore

$$
\bar{v}_{B r}=\frac{2}{\pi} v_{B r_{\text {peak }}}=\frac{2}{\pi} v_{C p_{\text {peak }}}=\frac{2}{\pi} \sqrt{v_{C p d}^{2}+v_{C p q}^{2}}
$$

- Power balance theory: Output power from AC subsystem is equal to input power to DC sub-system (assuming lossless reverse recovery in rectifier).

$$
\frac{1}{2}\left(v_{C p d} i_{B r d}+v_{C p q} i_{B r q}\right)=\bar{v}_{B r} i_{L o}
$$

Substituting (19) into (20) yields

$$
\frac{v_{C p d}}{\sqrt{v_{C p d}^{2}+v_{C p q}^{2}}} i_{B r d}+\frac{v_{C p q}}{\sqrt{v_{C p d}^{2}+v_{C p q}^{2}}} i_{B r q}=\frac{4}{\pi} i_{L o}
$$

As outlined by the analysis in [9], it can be also concluded that

$$
i_{B r_{\text {peak }}}=\frac{4}{\pi} i_{L o}=\sqrt{i_{B r d}^{2}+i_{B r q}^{2}}
$$

Through equations (21) and (22), the non-linear relationship between the $\mathrm{AC}$ and $\mathrm{DC}$ sub-systems of the series-parallel resonant converter is confirmed. Hence the voltage-current relationship can be represented by

$$
\begin{aligned}
& i_{B r d}=f\left(i_{L o}, v_{C p d}, v_{C p q}\right) \\
& i_{B r q}=f\left(i_{L o}, v_{C p d}, v_{C p q}\right)
\end{aligned}
$$

\section{State Feedback and Linearization}

In this section, linear state feedback is used to linearize the relationship between AC and DC sub-systems of the SPRC. 


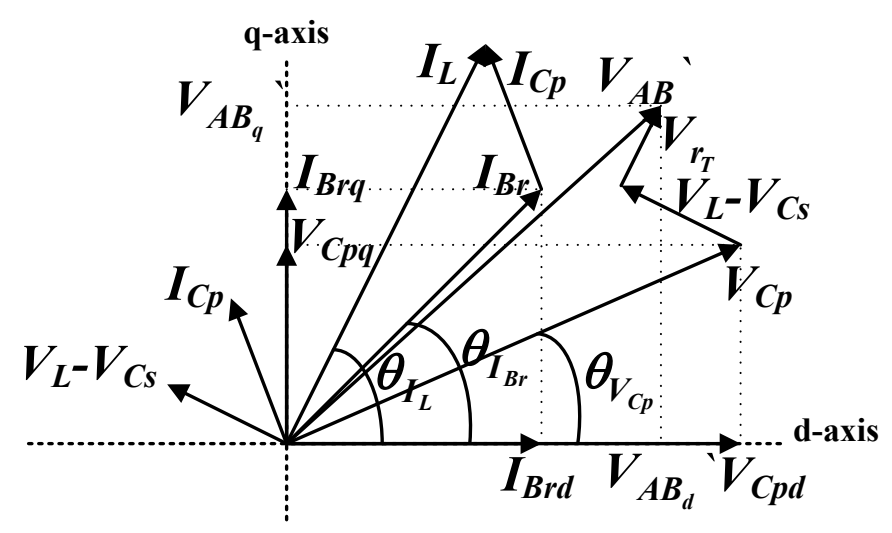

Fig. 6. Steady-state phasor diagram for AC sub-system.

\section{A. Steady-state analysis of AC sub-system}

Fig.6 shows steady-state phasor diagram analysis for the AC sub-system (resonant tank) assuming sinusoidal state variables. Capital notation denotes steady-state values. Starting with $v_{C p}$ and $i_{B r}$ and working backwards (as from Fig. 3), inverter voltage $v_{A B}{ }^{\prime}$ (referred to secondary) can be expressed as,

$$
\begin{aligned}
V_{A B d}= & V_{C p} \cos \theta_{V_{C p}}+\left(V_{L}-V_{C s}\right) \cos \left(90+\theta_{I_{L}}\right)+V_{r_{T}} \cos \theta_{I_{L}} \\
& =V_{C p d}+\left(\frac{1}{\omega_{s} C_{s}}-\omega_{s} L_{T}\right)\left(I_{B r q}+I_{C p} \cos \theta_{V_{C_{p}}}\right)+r_{T}\left(I_{B r d}+I_{C p} \cos \left(90+\theta_{V_{C p}}\right)\right) \\
& =V_{C p d}+\left(\frac{1}{\omega_{s} C_{s}}-\omega_{s} L_{T}\right)\left(I_{B r q}+V_{C p} \omega_{s} C_{p} \cdot \frac{V_{C p d}}{V_{C p}}\right)+r_{T}\left(I_{B r d}-V_{C p} \omega_{s} C_{p} \cdot \frac{V_{C p q}}{V_{C p}}\right) \\
& =V_{C p d}\left(1+\frac{C_{p}}{C_{s}}-\omega_{s}^{2} L_{T} C_{p}\right)+V_{C p q}\left(-r_{T} \omega_{s} C_{p}\right)+I_{B r d}\left(r_{T}\right)+I_{B r q}\left(\frac{1}{\omega_{s} C_{s}}-\omega_{s} L_{T}\right) \\
& =k_{1} V_{C p d}+k_{2} V_{C p q}+k_{3} I_{B r d}+k_{4} I_{B r q} \\
V_{A B q} & =V_{C p} \sin \theta_{V_{C p}}+\left(V_{L}-V_{C s}\right) \sin \left(90+\theta_{I_{L}}\right)+V_{r_{T}} \sin \theta_{I_{L}} \\
& =V_{C p q}-\left(\frac{1}{\omega_{s} C_{s}}-\omega_{s} L_{T}\right)\left(I_{B r d}+I_{C p} \sin \theta_{V_{C p}}\right)+r_{T}\left(I_{B r q}+I_{C p} \sin \left(90+\theta_{V_{C p}}\right)\right) \\
& =V_{C p d}-\left(\frac{1}{\omega_{s} C_{s}}-\omega_{s} L_{T}\right)\left(I_{B r d}-V_{C p} \omega_{s} C_{p} \cdot \frac{V_{C p q}}{V_{C p}}\right)+r_{T}\left(I_{B r q}+V_{C p} \omega_{s} C_{p} \cdot \frac{V_{C p d}}{V_{C p}}\right) \\
& =V_{C p d}\left(r_{T} \omega_{s} C_{p}\right)+V_{C p q}\left(1+\frac{C_{p}}{C_{s}}-\omega_{s}^{2} L_{T} C_{p}\right)+I_{B r d}\left(\omega_{s} L_{T}-\frac{1}{\omega_{s} C_{s}}\right)+I_{B r q}\left(r_{T}\right) \\
& =k_{5} V_{C p d}+k_{6} V_{C p q}+k_{7} I_{B r d}+k_{8} I_{B r q}
\end{aligned}
$$

where,

$$
\begin{aligned}
& k_{1}=k_{6}=\left(1+\frac{C_{p}}{C_{s}}-\omega_{s}^{2} C_{p} L_{T}\right), k_{2}=-k_{5}=-r_{T} \omega_{s} C_{p}, \quad k_{3}=k_{8}=r_{T} \quad \text { and } \\
& k_{4}=-k_{7}=\left(\frac{1}{\omega_{s} C_{s}}-\omega_{s} L_{T}\right)
\end{aligned}
$$

Expressions for steady-state parallel capacitor voltage $\left(V_{C p}\right)$ can be obtained by solving (24) and (25) simultaneously and re-arranging

$$
\begin{aligned}
& V_{C p d}=\frac{k_{6}}{k_{1} k_{6}-k_{2} k_{5}} V_{A B d}-\frac{k_{2}}{k_{1} k_{6}-k_{2} k_{5}} V_{A B q}+\frac{k_{2} k_{7}-k_{3} k_{6}}{k_{1} k_{6}-k_{2} k_{5}} I_{B r d}+\frac{k_{2} k_{8}-k_{4} k_{6}}{k_{1} k_{6}-k_{2} k_{5}} I_{B r q} \\
& V_{C p q}=-\frac{k_{5}}{k_{1} k_{6}-k_{2} k_{5}} V_{A B d}+\frac{k_{1}}{k_{1} k_{6}-k_{2} k_{5}} V_{A B q}+\frac{k_{3} k_{5}-k_{1} k_{7}}{k_{1} k_{6}-k_{2} k_{5}} I_{B r d}+\frac{k_{4} k_{5}-k_{1} k_{8}}{k_{1} k_{6}-k_{2} k_{5}} I_{B r q}
\end{aligned}
$$

Therefore, steady-state values for outputs of the AC subsystem $\left(V_{C p d}\right.$ and $\left.V_{C p q}\right)$ are obtained as function of inputs $\left(V_{A B d^{\prime}}, V_{A B q^{\prime}}{ }^{\prime} I_{B r d}\right.$ and $\left.I_{B r q}\right)$. This could be alternatively analyzed using state-space equation (15) at steady-state

$$
\begin{gathered}
0=A_{1} \vec{X}_{1}+B_{1} \vec{U} \\
\vec{X}_{1}=\left[\begin{array}{llllll}
I_{L d} & I_{L q} & V_{C s d} & V_{C s q} & V_{C p d} & V_{C p q}
\end{array}\right]^{T}=-A_{1}^{-1} B_{1}\left[\begin{array}{lllll}
V_{A B d} & V_{A B q} & I_{B r d} & I_{B r q}
\end{array}\right]^{T}
\end{gathered}
$$

\section{B. State compensation scheme}

According to (19)-(22), if $i_{B r q}=0$ then, $v_{C p q}=0, \bar{v}_{B r}=\frac{2}{\pi} v_{C p d}$ and $i_{B r d}=\frac{4}{\pi} i_{L o}$. This is explained in [9] by the equivalent AC resistive impedance at rectifier input given by (30).

$$
R_{a c}=\frac{V_{C p}}{I_{B r}}=\frac{\pi^{2}}{8} R_{L}
$$

This implies that phasors in Fig.6 for $V_{C p}$ and $I_{B r}$ are aligned on d-axis (i.e. $V_{C p}=V_{C p d}$ and $I_{B r}=I_{B r d}$ with zero q-axis components). To apply this to the resonant tank (AC sub-system) model, a synchronous reference frame is selected such that $I_{B r q}=0$. Angle of rotation $\omega_{s} t$ is aligned with $i_{B r}$ to ensure $I_{B r q}=0$ and $I_{B r}=I_{B r d}$. Substituting for $V_{C p q}=0$ and $I_{B r q}=0$ into equations (26) and (27), yields

$$
\begin{aligned}
& V_{A B d}{ }^{`}=k_{1} V_{C p d}+k_{3} I_{B r d} \\
& V_{A B q}{ }^{`}=k_{5} V_{C p d}+k_{7} I_{B r d}
\end{aligned}
$$

Equations (31) and (32) show that in case of $I_{B r q}=0$ and $V_{C p q}=0$, the resonant circuit input voltage $V_{A B}{ }^{\prime}$ is a function of $I_{B r d}$ (proportional to load current) and $V_{C p d}$ (proportional to output voltage). $V_{A B}$ ' has to follow the relationship outlined by (31) and (32) in order to satisfy the main criteria for linearizing the converter model $\left(I_{B r q}=0\right.$ and $\left.V_{C p q}=0\right)$ and to ensure stable converter operation. The AC sub-system (resonant tank) is fed with

$$
\begin{gathered}
v_{A B d}{ }^{`}=k_{1} v_{c}+k_{3} i_{B r d} \\
v_{A B q}{ }^{\prime}=k_{5} v_{c}+k_{7} i_{B r d}
\end{gathered}
$$

where, $v_{c}$ is a common control input. This scheme uses weighted state feedback approach to linearize the resonant converter model. The weighted compensation is implemented using the output filter inductor current $i_{L o}$ as shown in Fig. 7.

\section{Aggregate linear model}

A universal model for the resonant converter can be obtained by combining the two linear state-space models in (15) and (18). Taking (35) into account yields the aggregate model (36).

$$
\begin{aligned}
& \bar{v}_{B r}=\frac{2}{\pi} v_{C p d}, \quad i_{B r d}=\frac{4}{\pi} i_{L o}, \quad i_{B r q}=0, \\
& v_{A B d}=k_{1} v_{c}+\frac{4}{\pi} k_{3} i_{L o}, \quad v_{A B q}=k_{5} v_{c}+\frac{4}{\pi} k_{7} i_{L o} \\
& \vec{x}(\iota)=A \vec{x}(\iota)+D \vec{u}(\iota) \text { and } y(t)=C \vec{x}(\iota)
\end{aligned}
$$

where,

$\vec{x}(\iota)=\left\lfloor\iota_{L d} i_{L q} v_{C s d} v_{C s q} v_{C p d} v_{C p q} i_{L o} v_{o}\right]^{T}, \vec{u}(\iota)=\left\lfloor v_{c} \iota_{o}\right]^{T}, y(t)=v_{o}$ 


$$
A=\left[\begin{array}{cccccccc}
-\frac{r_{T}}{L_{T}} & \omega_{s} & -\frac{1}{L_{T}} & 0 & -\frac{1}{L_{T}} & 0 & \frac{4 k_{3}}{\pi L_{T}} & 0 \\
-\omega_{s} & -\frac{r_{T}}{L_{T}} & 0 & -\frac{1}{L_{T}} & 0 & -\frac{1}{L_{T}} & \frac{4 k_{7}}{\pi L_{T}} & 0 \\
\frac{1}{C_{s}} & 0 & 0 & \omega_{s} & 0 & 0 & 0 & 0 \\
0 & \frac{1}{C_{s}} & -\omega_{s} & 0 & 0 & 0 & 0 & 0 \\
\frac{1}{C_{p}} & 0 & 0 & 0 & 0 & \omega_{s} & -\frac{4}{\pi C_{p}} & 0 \\
0 & \frac{1}{C_{p}} & 0 & 0 & -\omega_{s} & 0 & 0 & 0 \\
0 & 0 & 0 & 0 & \frac{2}{\pi L_{o}} & 0 & -\frac{r_{L o}}{L_{o}} & -\frac{1}{L_{o}} \\
0 & 0 & 0 & 0 & 0 & 0 & \frac{1}{C_{o}} & 0
\end{array}\right]
$$

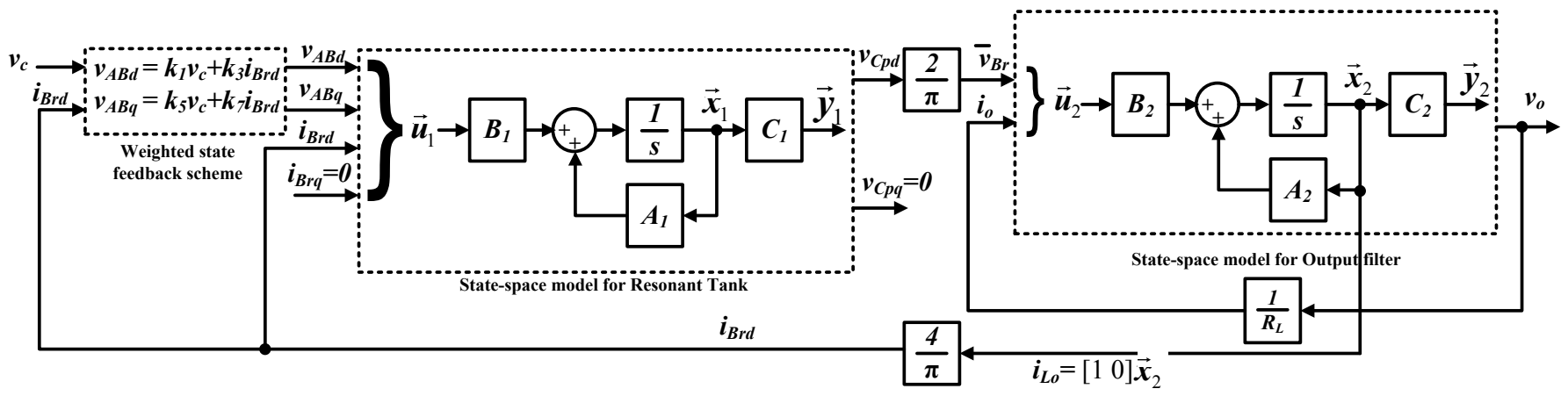

Fig. 7. Linearized model for the SPRC using weighted state feedback.

$$
\begin{aligned}
& B=\left[\begin{array}{cccccccc}
\frac{k_{1}}{L_{T}} & \frac{k_{5}}{L_{T}} & 0 & 0 & 0 & 0 & 0 & 0 \\
0 & 0 & 0 & 0 & 0 & 0 & 0 & -\frac{1}{C_{o}}
\end{array}\right]^{T} \\
& C=\left[\begin{array}{llllllll}
0 & 0 & 0 & 0 & 0 & 0 & 0 & 1
\end{array}\right]
\end{aligned}
$$

\section{Results And Discussion}

The accuracy of the linearized system model in (36) is investigated by comparing with detailed switching model of a 1 $\mathrm{kW}, 40 \mathrm{kHz}$ open loop phase-controlled SPRC. Simulations are performed using MATLAB/SIMULINK software. Fig. 8 shows the circuit diagram with the control algorithm used for state feedback. The closeness of the linearized SPRC model to real converter behavior is assessed by applying a step reference voltage $v_{c}=90 \frac{\pi}{2}$ volts $(t=0)$ and step load change ( $t=0.025 \mathrm{~s}$ ) from half load to full-load. Circuit parameters are given in Table II.

By comparing the weighted state feedback scheme in (33)(34) with (31)-(32), it is clear that at steady-state $v_{C p d}$ is equal to the control input voltage $v_{c}$, i.e. $V_{c p d}=V_{c}$. This explains why results for $v_{C p d}$ are constant at $v_{C p d}=v_{c}=90 \frac{\pi}{2} \mathrm{~V}$ (Fig. 9c).

TABLE II

RESONANT CONVERTER SIMULATION PARAMETERS Parameter Value

$\begin{array}{cc}\text { Full-load resistance } R_{L} & 8 \Omega \\ \text { Full-load quality factor } Q=\sqrt{L_{s} / C_{s}} / R_{L} & 2.565 \\ \text { Internal resistance of resonant tank inductor } r_{L s} & 0.2712 \Omega \\ \text { Resonant tank inductance } L_{s} & 99.81 \mu \mathrm{H} \\ \text { Parasitic transformer resistance referred to secondary } r_{l} & 0.096 \Omega \\ \text { Transformer Leakage inductance referred to secondary } L_{l} & 7.665 \mu \mathrm{H} \\ \text { Total equivalent resistance } r_{T}=r_{l}+r_{L s} & 0.3672 \Omega \\ \text { Total equivalent inductance } L_{T}=L_{l}+L_{s} & 107.475 \mu \mathrm{H} \\ \text { Resonant tank series capacitances } C_{s}=C_{p} & 0.255 \mu \mathrm{F} \\ \text { Internal resistance of output filter inductor } r_{L o} & 1 \Omega \\ \text { Output filter inductance } L_{o} & 10 \mathrm{mH} \\ \text { Output filter capacitance } C_{o} & 120 \mu \mathrm{F} \\ \text { Resonant tank fundamental frequency } f_{s}\left(\omega_{s}=2 \pi f_{s}\right) & 40 \mathrm{kHz}\end{array}$

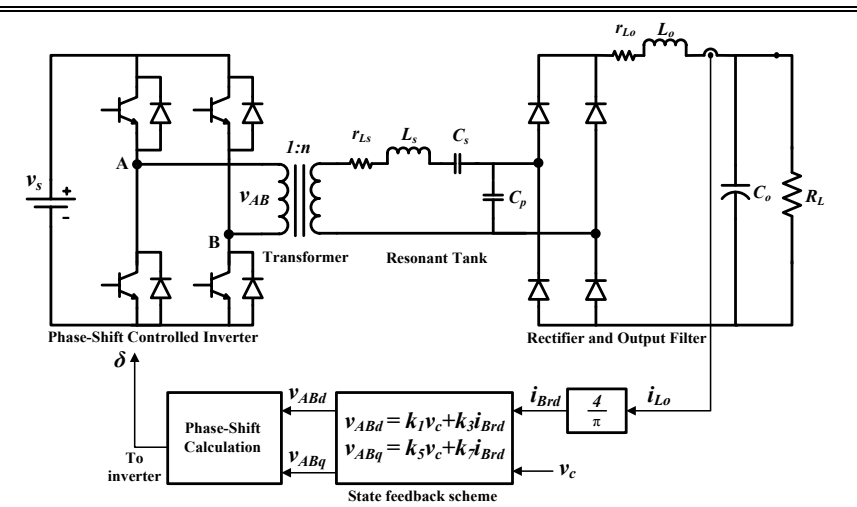

Fig. 8. Simulation diagram with state feedback algorithm for open loop fixedfrequency phase-shift control of SPRC 
The feedback linearization scheme causes $v_{C p q}=0$ at all loading conditions. Output voltage in Fig. 9a (ideally $v_{o}=\frac{2}{\pi} v_{C p d}=90 \mathrm{~V}$ ) follows a second order under-damped response due to the output filter dynamics. The voltage difference from the ideal $90 \mathrm{~V}$ output is due to drop on parasitic impedance of filter inductor. This increases at full-load. Voltage control is implemented using closed loop control. Transient and steady-state performance of the proposed linear statespace model almost tracks the exact switching model for all state variables (Fig. 9a-d).

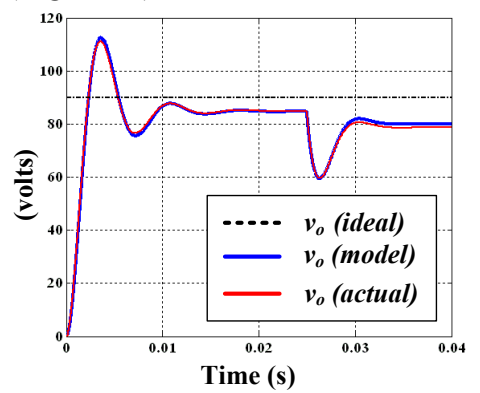

(a)

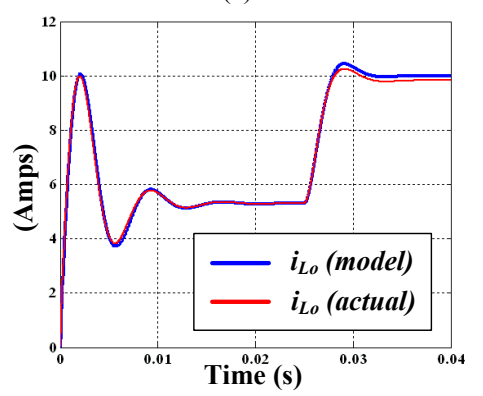

(b)

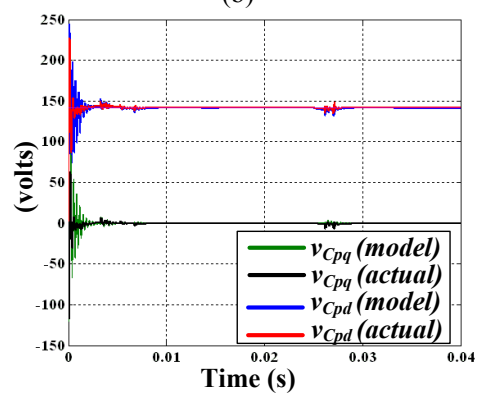

(c)

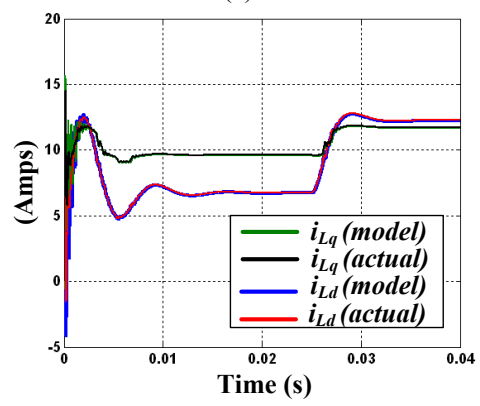

(d)

Fig. 9. Simulation results comparing actual switching and linearized large signal models (full-load at $\mathrm{t}=0.025 \mathrm{~s}$ ): (a) $v_{o}$, (b) $i_{L o}$, (c) $v_{C p_{d q}}$, (d) $i_{L_{d q}}$.
This paper proposes a feedback scheme from output filter inductor current to obtain a linearized large-signal model for the fixed-frequency phase-controlled SPRC. All state variables are converted to slowly changing DC quantities which are easier to control than the fast resonant tank dynamics. Simple PI control can be used for closed loop to provide infinite loop gain and eliminate steady-state error. The model accuracy compared to actual switching model proves that it is a promising tool for estimating large-signal state variable behavior of the converter.

\section{REFERENCES}

[1] Y. Lu, E. Cheng and S. L. Ho, "Quasi current mode control for the phaseshifted series resonant converter," IEEE Trans. on power electronics, vol. 23, no. 1, pp. 353-357, Jan. 2008.

[2] O. Lucia, J.M. Burdio, I. Millan and J. Acero, "Load-adaptive control algorithm of half-bridge series resonant inverter for domestic induction heating," IEEE Trans. on industrial electronics, vol. 56, no. 8, pp. 3106-3116, August 2009.

[3] H. Krishnasmawi and N. Mohan, "Three-port series-resonant DC-DC converter to interface renewable energy sources with bi-directional load and energy storage ports", IEEE Trans. on Power Electronics, vol. 24, no. 10, pp. 2289-2297, October 2009.

[4] R.J.King and T.A.Stuart, "Modelling the Full-Bridge Series-Resonant Power Converter", IEEE Trans. on Aerospace and Electronic Systems, vol. AES-18, no.4, pp. 449-459, July 1982.

[5] X. Li and A.K.S. Bhat, "Analysis and design of high frequency isolated dual-bridge series-resonant DC/DC converter", IEEE Trans. on Power Electronics, vol. 25, no.4, pp. 850-862, April 2010.

[6] Y-C. Chuang, Y-L. Ke, H-S. Chuang and H-K.Chen, "Implementation and analysis of an improves series-loaded resonant DC-DC converter operating above resonance for battery chargers," IEEE Trans. on Industry Applications, vol. 45 , no.3, pp. 1052-1059, June 2009.

[7] K. Siri, I. Batarseh, C.Q.Lee, "Frequency response for the conventional parallel resonant converter based on the state-plane diagram", IEEE Trans. on Circuits and Theory I: Fundamental Theory and Applications, vol. 40, no. 1, pp. 33-42, Jan 1993

[8] S.C.Wong and A.D.Brown, "Parallel resonant converter as a circuit simulation primitive," IEE Proceedings on Circuits, Devices and Systems, vol. 142, issue 6, pp. 379-386, 1995.

[9] Robert L. Steigerwald, "A comparison of Half-Bridge Resonant Converter Topologies", IEEE Trans. on Power Electronics, vol. 3, no.2, pp. 174-182, April 1988.

[10] A.K.S. Bhat, "Analysis and design of series-parallel resonant converter,", IEEE Trans. on Power Electronics, vol. 8, no.1, pp. 1-11, Jan 1993.

[11] S.C. Wong and A.D. Brown, "Analysis, modeling and simulation of series-parallel resonant converter circuits", IEEE Trans. on Power Electronics, vol. 10, no.5, pp. 605-614, Sept 1995.

[12] R. Oruganti and F. C. Lee, "Resonant Power Processors, Part II-Methods of Control", IEEE Trans. on industry applications, vol, IA-21, no.6, pp.14611471, Dec 1985.

[13] H. Chen, E.K.K.Sng, K-J Tseng, "Generalized optimal trajectory control for closed loop control of series-parallel resonant converter", IEEE Trans. on Power Elecronics, vol. 21, no. 5, pp. 1347, Sept 2006.

[14] P. Jain and J.E. Quaicoe, "Modeling and analysis of fixed-frequency phase-shift modulated tertiary-side parallel-tuned resonant DC/DC converter", IAS annual meeting 1993, pp. 1081-1089.

[15] D. Czarkowski and M. K. Kazimierczuk, "Phase-controlled seriesparallel resonant converter", IEEE Trans. on Power Electronics, vol. 8, no.3, July 1993.

[16] A.K.S. Bhat, "Fixed-frequency PWM series-parallel resonant converter,", IEEE Trans. on Industry Applications, vol. 28, no.5, pp. 1002-1009, Sept 1992.

[17] I.Batarseh and C.Q. Lee, "High-frequency high-order parallel resonant converter," IEEE Trans. on Industrial Electronics, vol. 36, no. 4, pp. 485-498, Nov. 1989.

[18] M.K.Kazimierczuk, N.Thirunaragan and S. Wang, "Analysis of seriesparallel resonant converter," IEEE Trans Aerospace Electronic Systems, vol. 29, no.1, pp. 278-287, Jan 1993.

\section{Conclusion}


[19] A.K.S. Bhat and S.B. Dewan, "Analysis and design of a high frequency resonant converter using LCC-type commutation", IEEE Trans. Power Electronics, vol. 8, no. 4, pp. 291-300, July 1993.

[20] I. Batarseh and K. Siri, "Generalized Approach to the small-signal modeling of DC-to-DC resonant converters", IEEE Trans. on Aerospace Electronic Systems, vol. 29, no.3, pp. 894-909, July 1993.

[21] V. Agarwal and A. K. S. Bhat, "Small signal analysis of the LCC-type parallel resonant converter using discrete time domain modeling", IEEE Trans. on Industrial Electronics, vol. 42, no. 6, pp. 604-614, Dec 1995.

[22] V. Agarwal and A. K. S. Bhat, "Dynamic analysis of the fixed-frequency PWM LCC-type parallel resonant converter using discrete time domain modeling”, PESC 1996, pp.272-278.

[23] S. Zheng and D. Czarkowski, "Dynamics of a phase-controlled seriesparallel resonant converter", ISCAS 2002, pp. 819-822.

[24] V. A. Caliskan, G. C. Verghese and A. M. Stankovic, "Multi-frequency averaging dc/dc converters," IEEE Trans. on power electronics, vol. 14, no.1, pp. 124-133, Jan 1999.

[25] S.R. Sanders, J.M. Noworolski, X.Z. Liu and G.C. Verghese, "Generalised Averaging Method for Power Conversion Circuits", IEEE Trans. on power electronics, vol. 6, no. 2, pp.251-259, April 1991.

[26] Z.M. Ye, P.K. Jain and P.C. Sen, "Modeling of High Frequency Resonant Inverter System in Phasor Domain for Fast Simulation and Control Design", PESC 2008, pp. 2090-2096.

[27] Z.M. Ye, P.K. Jain and P.C. Sen, "Multiple Frequency Modeling of High Frequency Resonant Inverter System", PESC 2004, pp. 4107-4113.

[28] V. Agarwal, V.K. Belaguli, "Large signal analysis using discrete time domain modeling for LCC-type parallel resonant converter operating in discontinuous current mode," CCECE 1993, pp. 80-83.

[29] V. Agarwal and A. K. S. Bhat, "Large signal analysis of the LCC-type parallel resonant converter using discrete time domain modeling", IEEE Trans. on Power Electronics, vol. 10, no. 2, pp. 222-238, March 1995.

[30] J.L. Sosa, M. Castilla, J. Miret, L. Garcia de Vicuna and J. Matas, "Modeling and performance analysis of the DC/DC series-parallel resonant converter operating with discrete self-sustained phase-shift modulation technique,", IEEE Trans. on Industrial Electronics, vol. 56, no. 3, pp. 697-705, March 2009.

[31] O. Ojo, "Robust control of series parallel resonant converters", IEE Proceedings on control theory and applications, vol. 142, issue 5, pp. 401-410, Sept 1995. 